\section{Macular thickness changes evaluated with spectral domain optical coherence tomography after uncomplicated phacoemulsification}

\begin{abstract}
Purpose To determine macular thickness changes after uncomplicated cataract surgery using spectral domain optical coherence tomography (OCT).

Methods This was a prospective nonrandomized, clinical study. Data were analysed for 40 healthy patients undergoing uneventful phacoemulsification. OCT measurements were performed before surgery and postoperatively at day 1 , week 1 and 2 , and month 1, 2, 3, and 6 . The retinal map was divided into central point thickness (CPT), central 1-mm subfield (CSF), and two peripheral ring areas with diameters of 3 and $6 \mathrm{~mm}$. Fellow eyes were used as controls. Retinal thickness change between the operated and fellow eyes were compared using unpaired $t$-test. Correlations were analysed using the Spearman or the Pearson analysis.

Results There was a progressive significant increase in retinal thickness of the operated eyes compared with the fellow eyes, with a peak at 1 month $(P<0.0001)$ for the 3 - and 6-mm areas and a peak at 2 months for CPT and CSF $(P=0.01$ and $P<0.0001$, respectively). At 6 months, retinal thickness was still significantly increased only in the peripheral areas $(P<0.0001)$. There was no significant correlation between macular thickness changes and preoperative factors (age, axial length, anterior chamber depth, posterior vitreous detachment, best-corrected visual acuity), intraoperative factors (length
\end{abstract}

M Gharbiya, F Cruciani, G Cuozzo, F Parisi, P Russo and S Abdolrahimzadeh

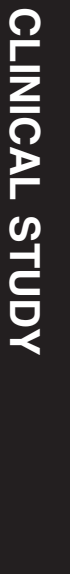

of surgery, effective phaco time, phaco energy) or BCVA change.

Conclusions The present study

demonstrated a significant increase in macular thickness up to 6 months after uncomplicated cataract surgery. The most important finding was the regional pattern of retinal thickening with an early involvement of the parafoveal area.

Eye (2013) 27, 605-611; doi:10.1038/eye.2013.28; published online 1 March 2013

Keywords: macular thickness; phacoemulsification; spectral domain optical coherence tomography; cystoid macular oedema

\section{Introduction}

Cystoid macular oedema (CMO), although infrequent with the advent of

phacoemulsification, is still a main cause of unfavourable visual outcome after uneventful cataract surgery. Pseudophakic clinically significant CMO is defined differently by various authors. When it is associated with a decrease in visual acuity of $20 / 40$ or worse, it is categorized as clinically significant. The incidence after phacoemulsification is reported to be $0.1-2 \%$ in healthy populations. ${ }^{1-5}$ Although the exact pathomechanism is not known, the role of surgical trauma with release of prostaglandins and blood retinal barriers disruption is suspected. ${ }^{6-7}$ Light toxicity and vitreo-macular traction may also have a role. ${ }^{4,8}$ Optical coherence tomography (OCT) has been
Department of Ophthalmology, Sapienza University, Umberto I Hospital, Rome, Italy

Correspondence: M Gharbiya, Department of Ophthalmology, Sapienza University-Umberto I Hospital, 155, Viale del Policlinico, Rome 00161 , Italy.

Tel: + 390649975302 ;

Fax: + 390649975304 ;

E-mail: magda.gharbiya@ tiscali.it

Received: 3 September 2012

Accepted in revised form: 22 January 2013 Published online: 1 March 2013 
used to study macular changes after uncomplicated cataract surgery and the results are heterogeneous; retinal thickness is increased in some studies, ${ }^{9-14}$ whereas in others a decrease is reported. ${ }^{15}$ These studies are difficult to compare due to the use of different generations of OCT instruments, data analysis, post-operative treatment regimens and probably a high incidence of measurement artefacts. Recently developed Spectralis OCT (Spectralis Family Acquisition Module; Heidelberg Engineering, Heidelberg, Germany) allows high resolution $(4-6 \mu \mathrm{m})$ and rapid imaging (40000 scan/s) with reduced motion artefacts. Furthermore, the embedded software of 'TruTrack active eye tracking', through the AutoRescan tool, allows to automatically place follow-up scans in precisely the same location as the baseline scan. This increases the clinician's ability to observe true change over time by avoiding alignment errors.

The purpose of this prospective study was to determine macular thickness changes by Spectralis OCT measurements after uncomplicated phacoemulsification in normal eyes. Furthermore, the regional pattern of thickness change was evaluated over time.

\section{Materials and methods}

A total of 45 eyes of 45 patients scheduled for cataract surgery in one eye at the Department of Ophthalmology of the University of Rome were enrolled between March and June 2011. The fellow eyes served as controls. Inclusion criteria were senile cataract in patients older than 50 years associated with visual impairment. Exclusion criteria were (1) pre-existing macular pathologies such as epiretinal membrane, macular hole or age-related macular degeneration; (2) other retinopathies such as retinal vascular occlusion or retinal dystrophy; (3) pre-existing ocular diseases such as glaucoma or uveitis; (4) amblyopia; (5) previous intraocular surgery or laser treatment except for cataract surgery in the fellow eye performed within the previous 12 months; (6) use of topical medication or systemic therapy with known interference on retinal thickness such as steroids and diuretics; (7) diabetes or other systemic disease that could affect the eye; and (8) lowquality or unreliable OCT images. All participants signed an informed consent filled in accordance with the Italian laws regarding privacy. The study was approved by the local Ethics Committee and conducted in accordance with the Declaration of Helsinki.

Preoperative evaluation included general medical history, a complete ophthalmological examination including best-corrected visual acuity (BCVA) measurement, biometry, and OCT of both eyes. BCVA was measured with the Snellen chart and the values were converted to the logarithm of the minimal angle of resolution $(\log \mathrm{MAR})$ units. Biometric data such as axial length and anterior chamber depth were obtained in both eyes using the IOLMaster (V 4.07; Carl Zeiss Meditec, Inc., Dublin, CA, USA). Spectral Domain OCT images were obtained through dilated pupils with Spectralis OCT (Spectralis Family Acquisition Module, V 5.1.3.0; Heidelberg Engineering) with Heidelberg Eye Explorer (V 1.6.2.0; Heidelberg). A raster horizontal $20^{\circ} \times 15^{\circ}$, 19line scan, with a reciprocal distance of $240 \mu \mathrm{m}$, cantered on the fovea was obtained for both eyes of each patient. More than 25 scans were averaged for each scan. All OCT examinations were performed by an experienced operator masked to the study. Only reliable OCT maps were selected and the correct recognition of the retinal boundaries, namely vitreo-retinal interface and RPEBruch membrane junction, by the OCT automated segmentation software was checked on each scan. The following values were extrapolated from the retinal map: (1) central point thickness (CPT), which represents the distance between the vitreo-retinal interface and the RPEBruch membrane junction at the centre of the foveal depression; (2) central 1-mm subfield (CSF), which corresponds to the mean retinal thickness in the central 1mm diameter area; (3) mean retinal thickness in the two surroundings ring areas with diameters of $3 \mathrm{~mm}$ and $6 \mathrm{~mm}$ with an average value automatically calculated for four equal quadrants. Data analysis was performed using the mean of the values of the four quadrants. The 19 OCT single scans, which build a map, were evaluated separately for qualitative changes, namely cystic changes, by an independent observer (GC). The eyes scheduled for surgery were divided into 3 groups based on the preoperative status of vitreo-retinal adhesion evaluated by combined fundus examination and OCT: absence of posterior vitreous detachment (PVD), incomplete PVD, and complete PVD. Clinically significant $\mathrm{CMO}$ was arbitrarily defined as macular thickening associated with definite cystic changes detected by OCT, associated with any amount of visual acuity decrease. Subclinical CMO was defined as macular thickening associated with definite cystic changes without visual impairment.

All patients received levofloxacin $0.5 \%$ drops quid from the day before surgery. Surgery was carried out after tropicamide 1\% drops 4 times at 10-min intervals in topical anaesthesia (Ropivacaine cloridrate $7.5 \mathrm{mg} / \mathrm{ml}$ ). The same surgeon (MG) performed standard stop-andchop phacoemulsification using the OZIL Torsional Handpiece of the Infinity Vision System (Alcon Inc., Forth Worth, TX, USA) and in-the-bag intraocular lens (IOL) implantation of a foldable hydrophobic acrylic IOL (Alcon SN60WF). The parameters recorded for each operation were length of surgery (minutes), effective phaco time (seconds), and phaco energy (\%). These were 
calculated by the Infinity software. Patients with any intraoperative complications such as posterior capsule rupture, vitreous loss and iris prolapse or manipulation were excluded from the study.

Post-operative regimen included levofloxacin $0.5 \%$ drops quid for 10 days and a combination of dexamethasone $0.2 \%$ and cloramphenicol $0.5 \%$ drops 4 times daily which was tapered by 1 drop daily each week. All patients were examined postoperatively at day 1, week 1 and 2 and month 1, 2, 3 and 6 using the preoperative protocol.

\section{Statistical analysis}

The sample size was calculated for a significance of 0.05 and a power of 0.80 with the commercial software IBM SPSS Sample Power for Windows (SPSS Inc., Chicago, IL, USA) and it was 37 patients. To account for a $10 \%$ dropout in follow-up, a total of 45 patients were recruited. Statistical analysis was performed with the SPSS for windows (V 17.0, SPSS). To reduce inter-individual variability data were analysed by comparing retinal thickness change between operated and fellow eyes. Normal distribution of data was analysed by the Kolmogorov-Smirnov test. Parametric variables were compared using the unpaired $t$-test. Non-parametric distributed values were analysed by the Mann-Whitney rank sum test. Repeatability for retinal thickness measurements in the operated and fellow eyes was tested with the intraclass test/retest correlation. Correlations between preoperative factors (age, axial length, anterior chamber depth, PVD, and BCVA), intraoperative factors (length of surgery, effective phaco time, and phaco energy) and the post-operative retinal thickness changes in the operated eyes were evaluated by the Spearman coefficient or the Pearson analysis as appropriate. Correlation between BCVA change and both CPT and CSF change after surgery was determined using the Spearman coefficient. $P$-values of less than 0.05 were considered as statistically significant.

We certify that all applicable institutional and governmental regulations concerning the ethical use of human volunteers were followed during this research.

\section{Results}

A total of 45 patients underwent uncomplicated phacoemulsification in one eye. Two patients decided to withdraw from the study ( $4.4 \%$ dropout rate). One eye was excluded because of intraoperative iris prolapse and manipulation, and two eyes (5\%) were excluded because of clinically significant $\mathrm{CMO}$ at 1 month after surgery. Consequently, a total of 40 eyes of 40 patients (16 male and 24 female) were analysed. Mean age ( \pm SD) was 62.1
( \pm 5.8 ) years (range; 52-69 years). Table 1 shows patient demographics together with preoperative and intraoperative characteristics of the studied eyes. In all, $26(65 \%)$ fellow eyes were phakic and $14(35 \%)$ eyes were pseudophakic. Preoperatively 21 eyes (52.5\%) had complete PVD, 14 eyes (35\%) had incomplete PVD, and 5 eyes $(12.5 \%)$ had no PVD. Mean $( \pm$ SD) effective phaco time was $83.8( \pm 32) \mathrm{s}$, phaco energy was $17.0( \pm 4.1 \%)$ and length of surgery was $10.5( \pm 2.8) \mathrm{min}$.

The average preoperative BCVA was significantly worse in the eyes scheduled for surgery. At all time points, average BCVA of the operated eyes was significantly improved with respect to that of the fellow eyes $(P<0.0001)$. (Figure 1$)$

Retinal thickness changes after surgery are shown in Table 2. On the first post-operative day, mean retinal thickness of all macular subfields of operated eyes decreased significantly compared with fellow eyes $(P<0.05)$. From the first week onwards, there was a progressive significant increase in retinal thickness of the outer macular area $(3 \mathrm{~mm}$ and $6 \mathrm{~mm})$ with a peak at 1 month $(P<0.0001)$. Retinal thickness of the central fovea (CPT and CSF) of the operated eyes began to significantly increase from the first month after surgery, with a peak at 2 months $(P=0.01$ and $P<0.0001$ for CPT and CSF, respectively). At 6 months, retinal thickness of the outer macular area of the operated eyes was still significantly increased $(P<0.0001)$, whereas there was no significant difference in retinal thickness of the central fovea $(P>0.05)$.

At all time points after surgery, none of the operated eyes, except for the CMO cases, showed a change in retinal thickness of more than $10 \%$ or above 2 SD of the preoperative mean macular retinal thickness measurements. In 2 eyes (5\%), we detected subclinical

Table 1 Patients' demographics, baseline and intraoperative characteristics

\begin{tabular}{lccc}
\hline & $\begin{array}{c}\text { Operated eyes } \\
(\mathrm{N}=40)\end{array}$ & $\begin{array}{c}\text { Fellow eyes } \\
(\mathrm{N}=40)\end{array}$ & P-value \\
\hline Male/female & $16 / 24$ & & \\
Age (years) & $62.1 \pm 5.8$ & & \\
Axial length (mm) & $23.31 \pm 1.31$ & $23.25 \pm 1.24$ & $0.8^{\mathrm{a}}$ \\
Anterior chamber & $3.22 \pm 0.48$ & $3.11 \pm 0.44$ & $0.3^{\mathrm{a}}$ \\
depth (mm) & & & \\
Baseline BCVA (logMAR) & $0.42 \pm 0.21$ & $0.10 \pm 0.17<0.0001^{\mathrm{b}}$ \\
CPT & $227.9 \pm 22.5$ & $228.0 \pm 21.0$ & $0.98^{\mathrm{a}}$ \\
1-mm CSF & $275.8 \pm 21.0$ & $279.4 \pm 20.1$ & $0.4^{\mathrm{a}}$ \\
3-mm area & $333.7 \pm 17.1$ & $336.2 \pm 19.3$ & $0.5^{\mathrm{a}}$ \\
6-mm area & $292.0 \pm 16.7$ & $293.0 \pm 17.8$ & $0.8^{\mathrm{a}}$ \\
Effective phaco time (s) & $83.84 \pm 32.01$ & & \\
Phaco energy (\%) & $16.95 \pm 4.14$ & & \\
Length of surgery (min) & $10.5 \pm 2.8$ & & \\
\hline
\end{tabular}

Abbreviations: CPT, central point thickness; CSF, central subfield.

a Unpaired $t$-test.

${ }^{\mathrm{b}}$ Mann-Whitney rank sum test. 


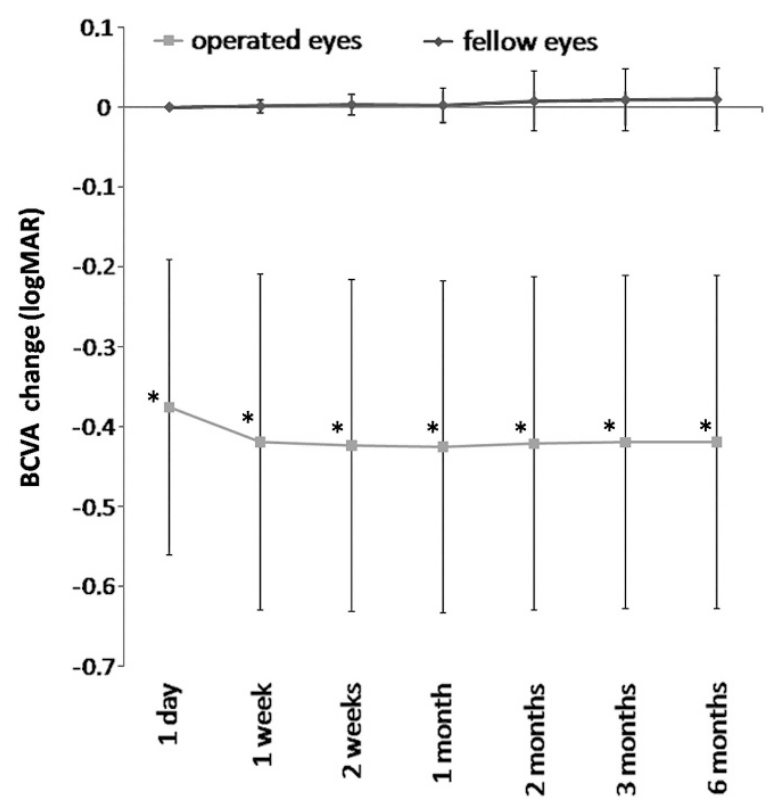

Figure 1 Macular thickness changes after uncomplicated phacoemulsification in a healthy population. Best-corrected visual acuity (BCVA) change in operated eyes and controls. $(*$, significant increase of BCVA between operated and fellow eyes; error bars indicate SD). cystic changes on OCT at 1 month after surgery that disappeared spontaneously in the subsequent examination.

The repeatability for the retinal thickness measurements was high in both the operated and fellow eyes. The intraclass correlation coefficients (ICC) in the operated eyes were 0.96 (95\% CI, 0.94-0.98), 0.97 (95\% CI, 0.95-0.98), 0.97 (95\% CI, 0.95-0.98), and 0.97 (95\% CI, 0.96-0.98) for CPT, CSF, 3-mm and 6-mm outer macular area, respectively. The ICCs in the fellow eyes were 0.96 (95\% CI, 0.94-0.98), 0.98 (95\% CI, 0.97-0.99), 0.98 (95\% CI, 0.97-0.99), and 0.97 (95\% CI, 0.95-0.98) for CPT, CSF, 3-mm and 6-mm outer macular area, respectively.

Correlation data are summarized in Table 3. Both postoperative CPT and CSF change did not correlate with BCVA change $(P>0.05)$. Furthermore, no significant correlations were found between retinal thickness changes and both the preoperative and intraoperative factors included in the analysis $(P>0.05)$.

\section{Discussion}

The present study demonstrated a decrease in retinal thickness in all macular subfields on the first day after

Table 2 Macular thickness measurements and the relative changes compared to baseline values in the operated and fellow eyes

\begin{tabular}{|c|c|c|c|c|c|c|c|}
\hline & 1 day & 1 week & 2 weeks & 1 month & 2 months & 3 months & 6 months \\
\hline \multicolumn{8}{|l|}{$C P T$} \\
\hline \multicolumn{8}{|l|}{ Operated eyes } \\
\hline $\begin{array}{l}\mathrm{RT} \pm \mathrm{SD} \\
\mathrm{RT} \text { change } \pm \mathrm{SD}\end{array}$ & $\begin{array}{c}224.5 \pm 21.1 \\
-2.4 \pm 4.4 \\
(P=0.01)^{\mathrm{a}}\end{array}$ & $\begin{array}{c}225.6 \pm 21.6 \\
-2.3 \pm 4.5 \\
(P=0.008)^{\mathrm{a}}\end{array}$ & $\begin{array}{c}228.2 \pm 22.3 \\
0.7 \pm 5.1 \\
(P=0.6)^{\mathrm{a}}\end{array}$ & $\begin{array}{c}232.0 \pm 21.1 \\
4.1 \pm 5.2 \\
(P=0.02)^{\mathrm{a}}\end{array}$ & $\begin{array}{c}233.1 \pm 22.3 \\
4.9 \pm 5.2 \\
(P=0.01)^{\mathrm{a}}\end{array}$ & $\begin{array}{c}231.0 \pm 21.0 \\
3.0 \pm 5.4 \\
(P=0.07)^{\mathrm{a}}\end{array}$ & $\begin{array}{c}227.9 \pm 20.7 \\
-0.1 \pm 7.3 \\
(P=0.7)^{\mathrm{a}}\end{array}$ \\
\hline \multicolumn{8}{|l|}{ Fellow eyes } \\
\hline $\mathrm{RT} \pm \mathrm{SD}$ & $229.1 \pm 20.3$ & $229.6 \pm 20.2$ & $230.6 \pm 21.1$ & $230.8 \pm 20.8$ & $231.4 \pm 21.3$ & $228.9 \pm 21.8$ & $227.5 \pm 20.9$ \\
\hline RT change \pm SD & $0.3 \pm 4.7$ & $0.1 \pm 3.3$ & $1.3 \pm 4.8$ & $1.3 \pm 4.7$ & $1.9 \pm 4.8$ & $0.9 \pm 4.8$ & $-0.6 \pm 5.8$ \\
\hline \multicolumn{8}{|l|}{ 1-mm CSF } \\
\hline \multicolumn{8}{|l|}{ Operated eyes } \\
\hline $\mathrm{RT} \pm \mathrm{SD}$ & $272.2 \pm 20.0$ & $274.4 \pm 20.7$ & $277.2 \pm 20.8$ & $282.0 \pm 21.3$ & $283.2 \pm 21.6$ & $281.6 \pm 21.2$ & $278.1 \pm 20.8$ \\
\hline RT change $\pm S D$ & $\begin{array}{c}-2.3 \pm 4.4 \\
(P=0.0001)^{\mathrm{a}}\end{array}$ & $\begin{array}{c}-1.4 \pm 4.5 \\
(P=0.001)^{\mathrm{a}}\end{array}$ & $\begin{array}{c}2.1 \pm 5.4 \\
(P=0.4)^{\mathrm{a}}\end{array}$ & $\begin{array}{c}6.2 \pm 5.1 \\
(P<0.0001)^{\mathrm{a}}\end{array}$ & $\begin{array}{c}7.0 \pm 4.6 \\
(P<0.0001)^{\mathrm{a}}\end{array}$ & $\begin{array}{c}5.8 \pm 4.4 \\
(P<0.0001)^{\mathrm{a}}\end{array}$ & $\begin{array}{c}2.3 \pm 4.2 \\
(P=0.06)^{\mathrm{a}}\end{array}$ \\
\hline \multicolumn{8}{|l|}{ Fellow eyes } \\
\hline $\mathrm{RT} \pm \mathrm{SD}$ & $280.4 \pm 20.6$ & $281.9 \pm 19.6$ & $280.8 \pm 19.9$ & $282.0 \pm 19.4$ & $282.7 \pm 20.6$ & $281.0 \pm 20.7$ & $279.7 \pm 20.5$ \\
\hline RT change \pm SD & $1.4 \pm 2.9$ & $1.5 \pm 2.8$ & $1.1 \pm 3.4$ & $1.6 \pm 3.0$ & $1.8 \pm 3.8$ & $1.5 \pm 3.9$ & $0.4 \pm 4.7$ \\
\hline \multicolumn{8}{|l|}{ 3-mm area } \\
\hline \multicolumn{8}{|l|}{ Operated eyes } \\
\hline $\mathrm{RT} \pm \mathrm{SD}$ & $331.9 \pm 18.1$ & $336.3 \pm 18.0$ & $338.7 \pm 17.7$ & $342.4 \pm 19.8$ & $342.2 \pm 18.6$ & $341.6 \pm 17.7$ & $338.9 \pm 18.4$ \\
\hline $\mathrm{RT}$ change $\pm \mathrm{SD}$ & $-1.3 \pm 4.0$ & $\begin{array}{c}2.5 \pm 4.1 \\
(P-0.008 \mathrm{a}\end{array}$ & $\begin{array}{c}5.7 \pm 4.2 \\
(P<0.0001)^{\mathrm{a}}\end{array}$ & $\begin{array}{c}8.7 \pm 5.5 \\
P(P-0001)^{a}\end{array}$ & $\begin{array}{c}8.5 \pm 4.5 \\
(P-0.501)^{a}\end{array}$ & $\begin{array}{c}7.9 \pm 3.8 \\
(P<00001)^{a}\end{array}$ & $\begin{array}{c}5.1 \pm 4.0 \\
(P<0.0001)^{\mathrm{a}}\end{array}$ \\
\hline \multicolumn{8}{|l|}{ Fellow eyes } \\
\hline $\mathrm{RT} \pm \mathrm{SD}$ & $335.6 \pm 20.3$ & $335.7 \pm 19.1$ & $334.3 \pm 18.5$ & $335.4 \pm 18.9$ & $335.5 \pm 18.9$ & $335.3 \pm 18.1$ & $335.7 \pm 19.4$ \\
\hline RT change \pm SD & $0.7 \pm 3.0$ & $0.4 \pm 2.8$ & $-0.3 \pm 2.5$ & $0.1 \pm 2.6$ & $-0.3 \pm 3.0$ & $-0.1 \pm 3.2$ & $-0.6 \pm 5.0$ \\
\hline \multicolumn{8}{|l|}{ 6-mm area } \\
\hline \multicolumn{8}{|l|}{ Operated eyes } \\
\hline $\mathrm{RT} \pm \mathrm{SD}$ & $291.8 \pm 17.7$ & $294.8 \pm 17.9$ & $296.8 \pm 17.3$ & $300.6 \pm 18.7$ & $300.2 \pm 17.5$ & $299.0 \pm 16.9$ & $296.8 \pm 17.1$ \\
\hline RT change \pm SD & $\begin{array}{l}-1.3 \pm 3.0 \\
(P=0.02)^{\mathrm{a}}\end{array}$ & $\begin{array}{c}2.8 \pm 3.5 \\
(P<0.0001)^{\mathrm{a}}\end{array}$ & $\begin{array}{c}5.2 \pm 3.8 \\
(P<0.0001)^{\mathrm{a}}\end{array}$ & $\begin{array}{c}8.6 \pm 4.6 \\
(P<0.0001)^{\mathrm{a}}\end{array}$ & $\begin{array}{c}7.9 \pm 4.3 \\
(P<0.0001)^{\mathrm{a}}\end{array}$ & $\begin{array}{c}7.0 \pm 3.8 \\
(P<0.0001)^{\mathrm{a}}\end{array}$ & $\begin{array}{c}4.8 \pm 3.4 \\
(P<0.0001)^{\mathrm{a}}\end{array}$ \\
\hline \multicolumn{8}{|l|}{ Fellow eyes } \\
\hline $\mathrm{RT} \pm \mathrm{SD}$ & $292.6 \pm 17.8$ & $291.3 \pm 17.3$ & $290.8 \pm 16.6$ & $290.7 \pm 17.2$ & $291.0 \pm 16.8$ & $291.0 \pm 15.8$ & $292.3 \pm 17.7$ \\
\hline RT change \pm SD & $0.3 \pm 2.5$ & $-0.3 \pm 2.6$ & $-0.4 \pm 2.4$ & $-1.0 \pm 2.6$ & $-0.9 \pm 3.6$ & $-0.8 \pm 4.3$ & $-0.7 \pm 6.2$ \\
\hline
\end{tabular}

Abbreviations: CPT, central point thickness; CSF, central subfield; RT, retinal thickness (microns).

${ }^{a}$ Retinal thickness changes between operated and fellow eyes were compared using the unpaired $t$-test. 
Table 3 Correlation data between retinal thickness change and preoperative and intraoperative parameters

\begin{tabular}{|c|c|c|c|c|c|c|c|c|}
\hline & \multicolumn{2}{|c|}{$C P T$} & \multicolumn{2}{|c|}{ 1-mm CSF } & \multicolumn{2}{|c|}{ 3-mm area } & \multicolumn{2}{|c|}{ 6-mm area } \\
\hline & $\begin{array}{c}\text { Correlation } \\
\text { coefficient }\end{array}$ & P-value & $\begin{array}{c}\text { Correlation. } \\
\text { coefficient }\end{array}$ & P-value & $\begin{array}{c}\text { Correlation } \\
\text { coefficient }\end{array}$ & P-value & $\begin{array}{c}\text { Correlation } \\
\text { coefficient }\end{array}$ & P-value \\
\hline Age (years) ${ }^{a}$ & 0.10 & 0.56 & -0.08 & 0.65 & -0.30 & 0.06 & -0.31 & 0.05 \\
\hline Baseline BCVA $(\log M A R)^{b}$ & -0.19 & 0.26 & -0.01 & 0.94 & - & - & - & - \\
\hline Axial length $(\mathrm{mm})^{\mathrm{a}}$ & -0.07 & 0.67 & 0.00 & 0.99 & 0.06 & 0.72 & 0.05 & 0.75 \\
\hline Anterior chamber depth $(\mathrm{mm})^{\mathrm{a}}$ & -0.07 & 0.71 & 0.07 & 0.67 & -0.03 & 0.87 & -0.10 & 0.56 \\
\hline Posterior vitreous detachment ${ }^{\mathrm{a}}$ & -0.13 & 0.42 & -0.04 & 0.80 & -0.16 & 0.32 & -0.18 & 0.27 \\
\hline Effective phaco time $(\mathrm{s})^{\mathrm{a}}$ & 0.16 & 0.43 & -0.02 & 0.92 & 0.07 & 0.73 & -0.01 & 0.97 \\
\hline Length of surgery $(\mathrm{min})^{\mathrm{b}}$ & 0.24 & 0.23 & -0.03 & 0.89 & -0.10 & 0.59 & -0.23 & 0.23 \\
\hline Phaco energy $(\%)^{\mathrm{b}}$ & 0.04 & 0.86 & 0.37 & 0.06 & 0.24 & 0.21 & 0.18 & 0.37 \\
\hline BCVA change $(\log M A R)^{b}$ & 0.16 & 0.33 & 0.03 & 0.88 & - & - & - & - \\
\hline
\end{tabular}

Abbreviations: CPT, central point thickness; CSF, central subfield.

a Pearson's correlation.

'spearman correlation.

uncomplicated cataract surgery. From the first week onwards, a progressive increase in retinal thickness was recorded with different trends over time of the central fovea (CPT and CSF) with respect to the outer macular area $(3 \mathrm{~mm}$ and $6 \mathrm{~mm})$. Spectralis OCT used in this study is characterized by a higher repeatability index. ${ }^{16}$ This is most probably related to the eye-tracking system and automatic recognition of the same scan location for follow-up examination. Thus, extrinsic factors, such as patient fixation and the operator's ability to consistently place the macular grid over the same points during each scan were minimized. Indeed, the repeatability indices for retinal thickness measurements in our study were very high in contrast to other reports. ${ }^{10,17}$ We did not observe substantial differences in the repeatability of measurements for CPT, CSF and 3-mm and 6-mm areas.

In previous studies, subclinical macular thickening has been reported after uncomplicated cataract surgery. ${ }^{9-14}$ Interestingly, in our study, at day 1 after surgery, mean retinal thickness of all macular subfields of the operated eyes decreased significantly in comparison to the fellow eyes. Retinal thickness on the first post-operative day showed significant increase in two studies ${ }^{9,10}$ and mild statistically insignificant decrease in one study. ${ }^{11}$ Therefore, our study is the first to show statistically significant decrease. It would seem reasonable to presume that retinal thickness does not vary or increase due to surgery-induced inflammation shortly after cataract extraction. Therefore, the significant decrease observed in our study could be related to the influence of lens opacity on the preoperative OCT measurements or to an apparent thinning of the retina when the lens is replaced by an IOL. Indeed, cataract may cause lightscattering effect that may give rise to artefacts in OCT measurements. ${ }^{18}$ Thus, the first post-operative day measurements might reflect the true 'baseline' retinal thickness. Alternatively, if the apparent reduction of macular thickness is related to the presence of an IOL, some adjustment in retinal thickness measurement by OCT may be required if the lens status is changed.

From the first week after surgery, there was a significant increase in retinal thickness of the outer macular area with a peak at 1 month, while retinal thickness of the central fovea began to increase from the first month, with a peak at 2. At 6 months after surgery, retinal thickness tended to normalize in the central fovea, whereas it remained increased in the outer macular area. This regional pattern of retinal thickening over time represents another peculiar finding of our study. Lobo $e t a l^{19}$ studied retinal leakage after uncomplicated phacoemulsification, using a prototype of confocal scanning laser fluorometer. The authors demonstrated in all (97\%) but one eye, the presence of retinal leaking sites located in the perifoveal zone. These leaking sites, which could represent focal inner BRB disruption, were located in the vascularized regions of the macula, outside the foveal avascular zone. This may explain the regional patterns of retinal thickening over time observed in our study.

A correlation between visual acuity and post-operative macular thickness increase has been found in two previous reports. ${ }^{9,14}$ However, in our study macular thickness increase was at subclinical level with no correlation between macular thickness changes and visual acuity. Interestingly, none of the preoperative and intraoperative parameters evaluated in this study, namely axial length, anterior chamber depth, status of vitreoretinal adhesion, length of surgery, effective phaco time and phaco energy, showed any correlation with retinal thickness changes after surgery. In particular, neither PVD nor phaco parameters, reported as potential factors that increase the likelihood of pseudophakic $\mathrm{CMO}$, had any correlation with retinal thickness changes. ${ }^{4,8}$

We did not find any difference in the repeatability for any of the retinal thickness measurements between 
operated and fellow eyes. None of the operated eyes, except for the two clinically significant CMO cases, showed a retinal thickness change more than $10 \%$ or above $2 \mathrm{SD}$ of the preoperative macular thickness measurements. This reflects that, in normal eyes, macular thickness changes recorded after uneventful cataract surgery, although statistically significant, are at subclinical level. This is an important finding because the use of new technology makes our results extremely reliable. Furthermore, it sheds light on the heterogeneous results of previous studies carried out using less-precise instrumentation.

In the present study, we reported a 5\% (2 eyes) incidence of clinically significant CMO. The higher incidence compared with previous studies $2,3,5,6$ may be due to our definition of clinically significant $\mathrm{CMO}$, based on 'any change' in visual acuity rather than a certain cutoff value. Furthermore, we reported a $5 \%$ incidence of macular cystic changes detected by OCT in the absence of visual impairment. Overall, the incidence of qualitative alterations detected by OCT in our study was $10 \%$. In the literature, the incidence of qualitative alterations, namely diffuse thickening or cystic changes is reported between 5 and $41 \% \cdot{ }^{14,19,20}$ Likely explanations for this discrepancy are the differences in patient recruitment criteria and the use of different post-operative treatment regimens. Indeed, antibiotic injection into the anterior chamber, different dosage and duration of topical steroidal therapy, and the use of topical non-steroidal anti-inflammatory agents may have biased the results of some of these studies.

In conclusion, Spectralis OCT provides objective and highly repeatable measurements of macular thickness allowing to reliably assess postsurgical retinal thickness changes. The present study demonstrated a significant increase in macular thickness with a peculiar regional pattern of distribution over time, where the most noteworthy changes were in the parafoveal area.

What was known before

- Macular thickness change using optical coherence tomography (OCT) has been reported after uneventful phacoemulsification but the results have been conflicting.

- Comparison of the reports in the literature is difficult due to the use of older generation OCT instruments and variable data analysis.

What this study adds

- Precise and highly repeatable OCT measurements of retinal thickness after uncomplicated phacoemulsification were obtained with the new technology.

- Our study showed a significant increase in macular thickness with a peculiar regional pattern of distribution over time, where the most significant changes were in the parafoveal areas.

\section{Conflict of interest}

The authors declare no conflict of interest.

\section{References}

1 Irvine SR. A newly defined vitreous syndrome following cataract surgery, interpreted according to recent concepts of the structure of the vitreous. Am J Ophthalmol 1953; 36: 599-619.

2 Ray S, D'Amico DJ. Pseudophacic cystoid macular edema. Semin Ophthalmol 2002; 17: 167-180.

3 Rosetti L, Autelitano A. Cystoid macular edema following cataract surgery. Curr Opin Opthalmol 2000; 11: 65-72.

4 Flach AJ. The incidence, pathogenesis and treatment of cystoid macular edema following cataract surgery. Trans Am Ophthalmol Soc 1998; 96: 557-634.

5 Mentes J, Erakgun T, Afrashi F, Kerci G. Incidence of cystoid macular edema after uncomplicated phacoemulsification. Ophthalmologica 2003; 217: 408-412.

6 Ursell PG, Spalton DJ, Whitcup SM, Nussenblatt RB. Cystoid macular edema after phacoemulsification: relationship to blood-aqueous barrier damage and visual acuity. J Cataract Refract Surg 1999; 25: 1492-1497.

7 Miyake K, Ibaraki N. Prostaglandins and cystoid macular edema. Surv Ophthalmol 2002; 47: 203-218.

8 Tranos PG, Wickremasinghe SS, Stangos NT, Topouzis F, Tsinopoulos I, Pavesio CE. Macular edema. Surv Ophthalmol 2004; 49: 470-490.

9 Nicholas S, Riley A, Patel H, Neveldson B, Purdie G, Wells AP. Correlations between optical coherence tomography measurement of macular thickness and visual acuity after cataract extraction. Clin Experiment Ophthalmol 2006; 34: 124-129.

10 Von Jagow B, Ohrloff C, Kohnen T. Macular thickness after uneventful cataract surgery determined by optical coherence tomography. Graefes Arch Clin Exp Ophthalmol 2007; 245: 1765-1771.

11 Perente I, Utine CA, Ozturker C, Cakir M, Kaya V, Eren H et al. Evaluation of macular changes after uncomplicated phacoemulsification surgery by optical coherence tomography. Curr Eye Res 2007; 32: 241-247.

12 Cagini C, Fiore T, Iaccheri B, Piccinelli F, Ricci MA, Fruttini D. Macular thickness measured by optical coherence tomography in a healthy population before and after uncomplicated cataract phacoemulsification surgery. Curr Eye Res 2009; 34: 1036-1041.

13 Biro Z, Balla Z, Kovacs B. Change of foveal and perifoveal thickness measured by OCT after phacoemulsification and IOL implantation. Eye 2008; 22: 8-12.

14 Kusbeci T, Eryigit L, Yavas G, Inan UU. Evaluation of cystoid macular edema using optical coherence tomography and fundus fluorescein angiography after uncomplicated phacoemulsification surgery. Curr Eye Res 2012; 37: 327-333.

15 Ching H-Y, Wong AC, Wong C-C, Woo DC, Chan CW. Cystoid macular oedema and changes in retinal thickness after phacoemulsification with optical coherence tomography. Eye 2006; 20: 297-303.

16 Wolf-Schnurrbusch UE, Ceklic L, Brinkmann CK, Iliev ME, Frey M, Rothenbuehler SP et al. Macular thickness measurements in healthy eyes using six different optical coherence tomography instruments. Invest Ophthalmol Vis Sci 2009; 50: 3432-3437. 
17 Chan A, Duker JS, Ko TH, Fujimoto JG, Schuman JS. Normal macular thickness measurements in healthy eyes using Stratus optical coherence tomography. Arch Ophthalmol 2006; 124: 193-198.

18 van Velthoven ME, van der Linden MH, de Smet MD, Faber DJ, Verbraak FD. Influence of cataract on optical coherence tomography image quality and retinal thickness. $\mathrm{Br} J$ Ophthalmol 2006; 90: 1259-1262.
19 Lobo CL, Faria PM, Soares MA, Bernardes RC, Cunha-Vaz JG. Macular alterations after small incision cataract surgery. J Cataract Refract Surg 2004; 30: 752-760.

20 Eriksson U, Alm A, Bjärnhall G, Granstam E, Matsson AW. Macular edema and visual outcome following cataract surgery in patients with diabetic retinopathy and controls. Graefes Arch Clin Exp Ophthalmol 2011; 249: 349-359. 